\title{
Introducing A Research Agenda for Family Business
}

\author{
Andrea Calabròl
}

It is clear that the Family Business Research field has gone through different stages of development and has made important contributions not only within the field but also to mainstream fields of research extending, integrating, and challenging their core assumptions. The field is in its maturity and an effort is needed to renew and energize its trajectory and especially set the stage for what is about to come in the future. The aim of this book has been to challenge junior and senior scholars and practitioners who are very close or interested to the family business phenomenon with the following question: what will be important in 2020-30 for the field and for family businesses? The book includes contributions which are visionary and provocative in terms of theory, methods, topics, and context of analysis and that can outline the potential routes for further developing the family business research field.

The book is organized in 17 chapters which have been developed by 46 international scholars from 17 different countries. The authors come from different research fields often bringing a multi-disciplinary approach such as history, sociology, and technology. The topics covered are manifold and include, among others: new family trends, history and family business, entrepreneurial legacy, mental models, board diversity, ethnic minorities, sense-making, creativity, Indian family business, spatial-familiness, corruption, financing, innovation, and digital business transformation.

Looking more specifically at the different chapters included in this book, Chapter 1 suggests that since the emergence of the field of family business, families have changed profoundly and will not stop changing in the future. The chapter explicates trends in the family system and their implications for practice and research in terms of how family businesses are owned, managed, and transferred to the next generation. 
Stemming from a sociological approach Chapter 2 explores the economic, social, political, and demographic changes that impact how a variety of family types are formed, arranged, and given meaning. It suggests that family business scholars bring a "sociological imagination" to their research by exploring a variety of different types of families to provide greater insight into family firm heterogeneity and the factors that impact firm outcomes.

Chapter 3 outlines ways that history is both a source of evidence and a collection of methods for developing insights about family business. Different methods used in history research are identified that explore reportage (sources of evidence), explanation (the contextualization of sources in time and place), understanding (engagement in the motives, thoughts, and emotions of the historical actors themselves), and evaluation.

Another important issue investigated in Chapter 4 is the dilemma faced by many family business owners: should they hire their own children into the business or not. They wonder how working in their family business influences their children. Some may consider how it impacts the child-parent relationship. Through two longitudinal studies, the authors provide empirical support for the positive effect of working in one's family business during adolescence.

Chapter 5 explores the concept of “entrepreneurial legacy" or the family's narrative reconstruction of past entrepreneurial achievements or resilience. Entrepreneurial legacy in business families is approached as both a multi-level and multi-temporal phenomenon. The authors argue that business family members develop particular multi-temporal mindsets that enable them to navigate their family's and firm's history while making present and future-related decisions.

Chapter 6 shows that in addition to improving wages and working conditions, providing meaningful and satisfactory work for employees is mandatory for family firms to succeed. The authors dichotomize company leaders' HR mental models as commitment- versus control-oriented, and explore how the interactions of loose versus tight family control and Theory X versus Theory $\mathrm{Y}$ HR models impact employees' work life quality.

Chapter 7 examines board diversity and its potential effects on family firm entrepreneurial outcomes. To do this, the authors use a novel perspective on family business entrepreneurial outcomes - effectuation - whose basis in practical cognitive/behavioral problem solving has demonstrated its value to understanding entrepreneurial decision-making. 
Chapter 8 highlights and conceptualizes the overlaps between family business and migration as a working model for future analysis and highlights a number of key areas for future research. This sometime artificial distinction is especially important where research is developed into practice. The development of appropriate support systems through formal and informal networks is a key priority for communities, economies, and the success of the family themselves.

Chapter 9 establishes a framework for investigating the ways in which family firms cope with the challenges of managing strategic and organizational choices by using the sense-making construct. Sense-making facilitates strategic and organizational decision-making during periods of change. Sense-making refers to the extent to which people are effective in integrating challenging/ uncertain events into a framework of shared meaning.

Chapter 10 explores creativity in family businesses, investigating what hinders or fosters creativity in the organizational context of family firms. Psychological Capital (PsyCap) is introduced as a potential tool to analyse creativity in family firms.

Chapter 11 provides a brief historical account of the family businesses in India and traces the evolution of the leading family enterprises across different eras. The authors look back to look ahead in identifying some of the factors that explain the resilience of thriving multi-generational family businesses and the emergence of new generation family businesses as well as the reasons for the decline of some of the erstwhile successful family ventures.

Chapter 12 examines the nexus between family firms and economic spaces by considering the influence of different types of economic spaces on firm behavior and performance and by attempting to clarify the role played by family firms in different economic spaces.

Chapter 13 explores whether and how the presence of an owning family influences the multi-national enterprise's (MNEs) transparency in host countries and, more precisely, how family-owned MNEs cope with the specific risk of corruption.

Chapter 14 discusses the state of the art on family business growth literature and the literature on the sources of finance to support this growth, with a focus on bank financing, mezzanine financing, and private equity.

The focus of Chapter 15 is on the innovation activities within an enterprising family business group. The authors take a perspective of innovation sourcing 
mechanisms and identify the ways, ranging from observation to mergers, in which the external knowledge sources were accessed.

Chapter 16 focuses on the specific opportunities and challenges faced by family firms related to digitalization and Chapter 17 explores the role of owning families in the digital business transformation of family firms, illustrating how they influence its implementation and success.

All chapters have a final table which includes the views the authors have on developing new research avenues. Each table shows specific research trajectories on the topic discussed suggesting some specific themes and for each of them, a set of research questions.

This book is intended for any type of audience. Interested readers who are new to the family business debate may find inspiration in some chapters and use the future research directions shown at the end of the chapters to further explore the topic. PhD students and junior readers would benefit from this book as it provides them with a unique chance to access views and concepts which could become dominating in the next decade for family business research and practice. Finally, it should also be interesting to practitioners as through this book they might reflect on the current challenges they are facing or on the ones which are about to come.

\section{Note}

1. andrea.calabro@ipag.fr 